\title{
Simulation Study of Space Vector Pulse Width Modulation Feeding a Three Phase Induction Motor
}

\author{
Rahim Ildarabadi ${ }^{1}$, Azadeh Ahmadi ${ }^{2}$ \\ Hakim Sabzevari University
}

*Corresponding Author: Rahim Ildarabadi, Hakim Sabzevari University, Iran

\begin{abstract}
This paper presents a simulation of a space-vector Pulse Width Modulation (SVPWM) inverter feeding a three-phase induction motor. The SVPWM inverter enables to feed the motor with a higher voltage with low harmonic distortions than the conventional sinusoidal PWM inverter. The voltagelfrequency control method is used for open loop speed control of induction motor.
\end{abstract}

Keywords: Space Vector, Pulse Width Modulation, Induction Motor

\section{INTRODUCTION}

Induction motors are widely used in both industrial and household applications due to their excellent specifications. They are simple in structure(An induction motor does not require mechanical commutation, separate-excited or self- excitation for all or part of the energy transferred from stator to rotor, as in universal, DC and large synchronous motors.), rugged, reliable (maintenance less) and economical.

In the past, application such as electric overhead cranes were using dc drives or wounded rotor motors (WRIM) with slip rings for rotor circuit connection to variable external resistance allowing considerable range of speed control. Resistor losses associated with low speed operation of WRIM is a major cost disadvantage, especially for constant loads [1].

With the development of semiconductor power electronics, in most of industrial variable-speed applications, DC and WIRM drives are being displaced by Variable frequency Drive-fed cage induction motors [2].

Pulse Width Modulation technique is one of the most popular methods and started to be used in the control of VFD-fed AC motors in the 1960s [3].There are different algorithms for PWM control such as Delta-modulation, Delta-Sigma modulation, Space Vector modulation, and so on.

The space vector pulse width modulation (svpwm) has become an approved PWM technique for three-phase voltage-source inverters in the control of AC motors [4].

In compared with the conventional sinusoidal PWM inverters, the svpwm is used to offer $15 \%$ increase in the dc-link voltage utilization and low output harmonic distortions [5].

The paper presents the detailed Matlab simulation of SVPWM inverter feeding a three-phase induction motor.

\section{SPACE-VeCtor Modulation TECHNIQUE}

The power circuit model of a three-phase voltage source inverter is shown in Fig $1 . V_{d c}$ is the inverter input voltage and $\mathrm{V}_{\mathrm{a}}, \mathrm{V}_{\mathrm{b}}, \mathrm{V}_{\mathrm{c}}$ are the output voltages applied to the star-connected motor windings. $\mathrm{S}_{1}$ through $S_{6}$ are the six power switches, which are controlled by switching variables $a, a,, b, b ', c$ and c'. The on and off states of the lower power switches are opposite to the upper one in a leg. 


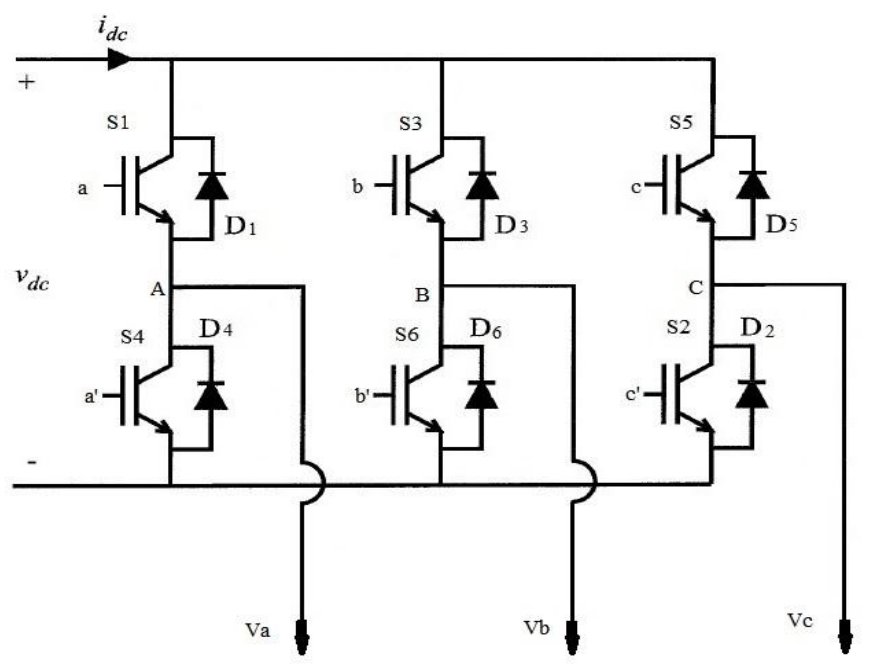

Fig1. Power circuit model of a three-phase voltage source inverter

There are eight different combinations of switching states as follows: (000), (100), (110), (010), (011), (001), (101), and (111), which makes eight active space vectors and two zero vectors that are shown in the complex space-vector plane in fig. $2 . \mathrm{V}_{0}, \mathrm{~V}_{7}$ are called zero vectors and do not cause a current to flow to the motor, so the line to line voltages are zero. The other six vectors, $V_{1}$ through $V_{6}$ can produce voltages to be applied to the motor terminals. The magnitudes of all six active vectors are equal and there is a $60^{\circ}$ phase displacement between each two adjacent vectors.

The general expression for the eight voltage vectors is [6]:

$V_{\text {six }- \text { step }, k}=\left\{\begin{array}{rr}\frac{2}{3} V_{d c} \exp \left(j \frac{(k-1) \pi}{3}\right), k=1, \ldots, 6 \\ 0 \quad, k=0,7\end{array}\right.$

The maximum fundamental phase voltage magnitude that may be produced by the inverter for a given dc link voltage occurs under six-step operation, and is given by:

$V_{1, \text { six-step }}=\frac{2}{\pi} V_{d c}$

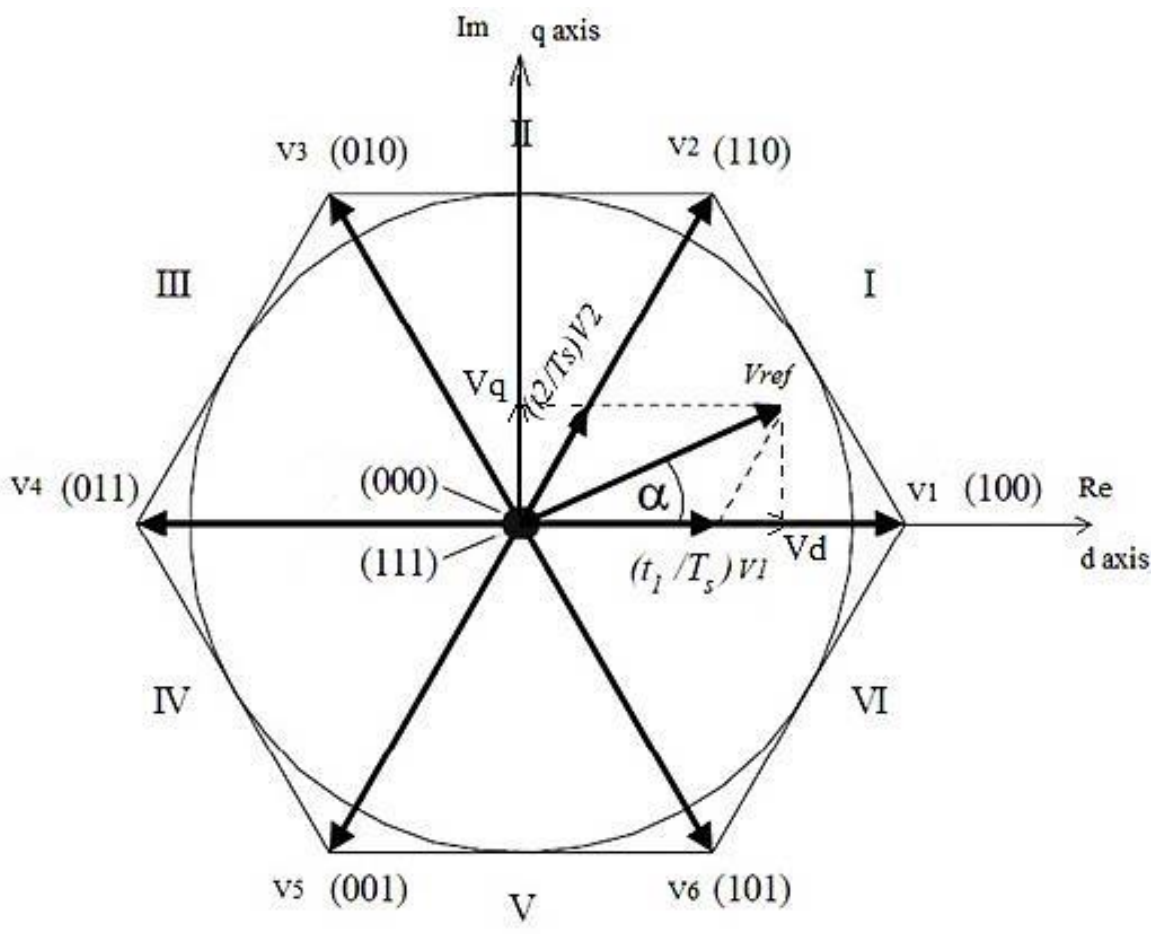

Fig. 2. Principle of the space vector modulation 
The desired voltage space at any particular instant may be written in Cartesian coordinate as:

$\vec{V}_{\text {ref }}=V_{d}+j V_{q}$

Which,

$\left|V_{\text {ref }}\right|=\sqrt{V_{d}^{2}+V_{q}^{2}}$ and $\alpha=\tan ^{-1}\left(\frac{V_{q}}{V_{d}}\right)$

as it shown in figure 2 .

Also, the relation between reference voltage vector, $V_{\text {ref }}$, and line to neutral voltages, $V_{a n}, V_{b n}$ and $V_{c n}$, is as follows, which is shown in Fig 3.

$\vec{V}_{\text {ref }}=\frac{2}{3}\left[1 \cdot V_{a n}+\boldsymbol{a} \cdot V_{b n}+\boldsymbol{a}^{2} \cdot V_{c n}\right]$

where: $a=e^{j \frac{2}{3} \pi}$ and $a^{2}=e^{j \frac{4}{3} \pi}$ represent the spatial operators.

Therefore, relation between $\mathrm{V}_{\mathrm{abc}}$ and $\mathrm{V}_{\mathrm{dq}}$ using Clarke transformation is as follows:

$\left[\begin{array}{l}V_{d} \\ V_{q}\end{array}\right]=\frac{2}{3}\left[\begin{array}{ccc}1 & -\frac{1}{2} & -\frac{1}{2} \\ 0 & \frac{\sqrt{3}}{2} & -\frac{\sqrt{3}}{2}\end{array}\right]\left[\begin{array}{l}V_{a n} \\ V_{b n} \\ V_{c n}\end{array}\right]$

The objective of SVPWM technique is to approximate the reference voltage vector $\mathrm{V}_{\text {ref }}$ using the eight switching states. In the each sector $\mathrm{V}_{\text {ref }}$ is obtainable by switching on, for a proper time, two adjacent vectors. Presented in fig 2 the reference vector $V_{\text {ref }}$ can be implemented by the switching vectors of $\mathrm{V} 1, \mathrm{~V} 2$ and zero vectors $\mathrm{V} 0, \mathrm{~V} 7$.

The reference voltage vector $V_{\text {ref }}$ is sampled with the fixed clock frequency $f_{s}=1 / T_{s}$.

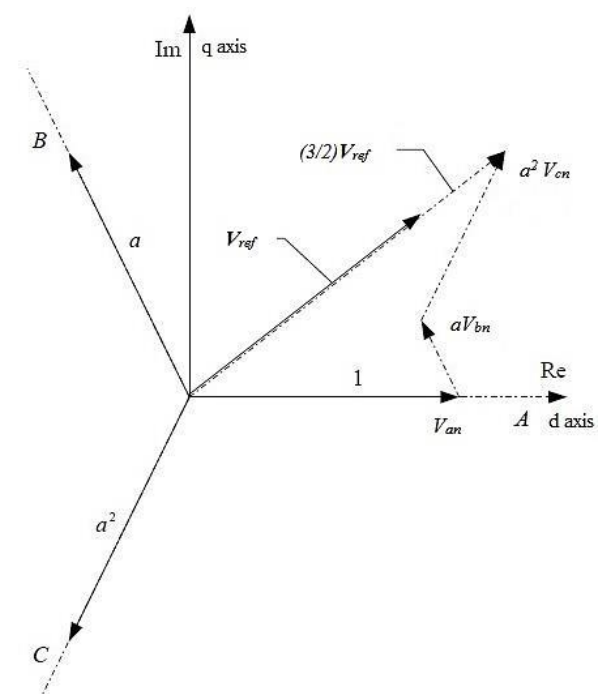

Fig3. Construction of space vector according to the definition (2.5)

The times $\mathrm{t} 1$ and $\mathrm{t} 2$ are obtained from simple trigonometric relationships as described in Fig.4.

$\mathbf{V}_{\text {ref }}=\left(\frac{t_{1}}{T_{\mathrm{s}}}\right) \mathbf{V}_{1}+\left(\frac{\mathrm{t}_{2}}{\mathrm{~T}_{\mathrm{s}}}\right) \mathbf{V}_{2}$

$\left(\frac{t_{1}}{T_{s}}\right) \mathbf{V}_{1}=\mathbf{V}_{r e f} \cos \alpha-B C=\mathbf{V}_{r e f} \cos \alpha-D C \tan 30^{\circ}=\mathbf{V}_{r e f} \cos \alpha-\mathbf{V}_{r e f} \sin \alpha \tan 30^{\circ}$

$$
\begin{aligned}
& =\mathbf{V}_{r e f}\left(\cos \alpha-\frac{1}{\sqrt{3}} \sin \alpha\right)=\frac{2}{\sqrt{3}} \mathbf{V}_{\text {ref }}\left(\sin 60^{\circ} \cos \alpha-\cos 60^{\circ} \sin \alpha\right) \\
& =\frac{2}{\sqrt{3}} \mathbf{V}_{\text {ref }} \sin \left(60^{\circ}-\alpha\right)
\end{aligned}
$$

$\left(\frac{t_{2}}{T_{s}}\right) \mathbf{V}_{2}=\frac{A O}{\cos 30^{\circ}}=\frac{\mathbf{V}_{r e f} \sin \alpha}{\sqrt{3} / 2}=\frac{2}{\sqrt{3}} \mathbf{V}_{r e f} \sin \alpha$ 


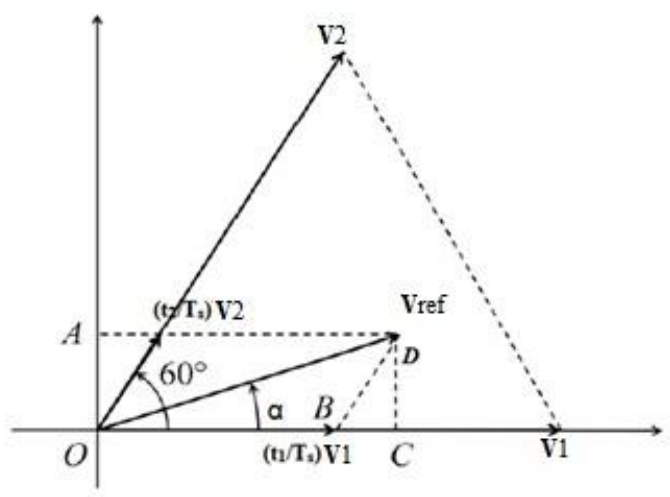

As the amplitude of $\mathrm{V} 1$ and $\mathrm{V} 2$ are equal to $2 \mathrm{~V}_{\mathrm{dc}} / 3$, hence:

$\boldsymbol{t}_{\mathbf{1}}=\sqrt{\mathbf{3}} \boldsymbol{T}_{\boldsymbol{s}} \frac{\mathbf{v}_{r e f}}{\mathbf{v}_{\boldsymbol{d c}}} \sin (60-\alpha)$

$\boldsymbol{t}_{\mathbf{2}}=\sqrt{\mathbf{3}} \boldsymbol{T}_{\boldsymbol{s}} \frac{\mathbf{v}_{r e f}}{\mathrm{~V}_{d c}} \sin \alpha$

After calculation of $t 1$ and $t 2$ from equations (2.8) the residual sampling time is reserved for zero vectors V0 and V7.

$T_{0}=T_{s}-\left(t_{1}+t_{2}\right)=t_{0}+t_{7}$

The equations for $\mathrm{t} 1$ and $\mathrm{t} 2$ are identically for all space vector modulation methods.

The only difference between the other types of SVM is the placement of zero vectors at the sampling time.

The basic SVM method is the modulation method with symmetrical spacing zero vectors (SVPWM). In this method times t0 and $\mathrm{t} 7$ are equal:

$t_{0}=t_{7}=T_{0} / 2$

For sector number $\mathrm{n}(\mathrm{n}=1 \ldots 6)$, the above equations can be generalized as follows:

$t_{\mathbf{1}}=\sqrt{\mathbf{3}} T_{s} \frac{\mathbf{v}_{r e f}}{\mathbf{v}_{d c}} \sin \left(\frac{n}{3} \pi-\alpha\right)$

$t_{2}=\sqrt{3} T_{s} \frac{\mathbf{v}_{r e f}}{V_{d c}}\left(\sin \left(\alpha-\frac{n-1}{3} \pi\right)\right)$

$t_{0}=t_{7}=T_{0} / 2$

After computing the active and zero state times for a particular modulation cycle, it is possible to produce the switching signals, $\mathrm{Sa}, \mathrm{Sb}$, and $\mathrm{Sc}$ to be applied to the inverter. Inverter switching signals for SVPWM in sector 1 is shown in fig. 5 and summarized in Table I for all vectors.

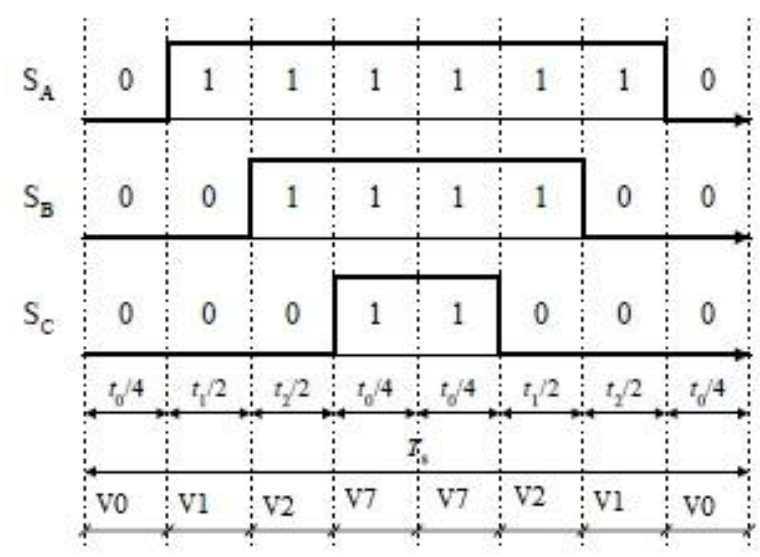

Fig5. Inverter switching signals for SVPWM in Sector 1 
Table1. Switching on Time at Each Sector

\begin{tabular}{|c|c|c|}
\hline $\mathrm{S}$ e c t o r & 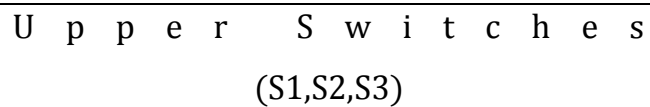 & 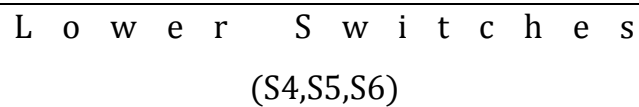 \\
\hline 1 & $\begin{array}{l}S_{1}=t_{1}+t_{2}+T_{0} / 2 \\
S_{3}=t_{2}+T_{0} / 2 \\
S_{5}=T_{0} / 2\end{array}$ & $\begin{array}{l}S_{4}=T_{0} / 2 \\
S_{6}=t_{1}+T_{0} / 2 \\
S_{2}=t_{1}+t_{2}+T_{0} / 2\end{array}$ \\
\hline 2 & $\begin{array}{l}S_{1}=t_{1}+T_{0} / 2 \\
S_{3}=t_{1}+t_{2}+T_{0} / 2 \\
S_{5}=T_{0} / 2\end{array}$ & $\begin{array}{l}S_{4}=t_{2}+T_{0} / 2 \\
S_{6}=T_{0} / 2 \\
S_{2}=t_{1}+t_{2}+T_{0} / 2\end{array}$ \\
\hline 3 & $\begin{array}{l}S_{1}=T_{0} / 2 \\
S_{3}=t_{1}+t_{2}+T_{0} / 2 \\
S_{5}=t_{2}+T_{0} / 2\end{array}$ & $\begin{array}{l}S_{4}=t_{1}+t_{2}+T_{0} / 2 \\
S_{6}=T_{0} / 2 \\
S_{2}=t_{1}+T_{0} / 2\end{array}$ \\
\hline 4 & $\begin{array}{l}S_{1}=T_{0} / 2 \\
S_{3}=t_{1}+T_{0} / 2 \\
S_{5}=t_{1}+t_{2}+T_{0} / 2\end{array}$ & $\begin{array}{l}S_{4}=t_{1}+t_{2}+T_{0} / 2 \\
S_{6}=t_{2}+T_{0} / 2 \\
S_{2}=T_{0} / 2\end{array}$ \\
\hline 5 & $\begin{array}{l}S_{1}=t_{2}+T_{0} / 2 \\
S_{3}=T_{0} / 2 \\
S_{5}=t_{1}+t_{2}+T_{0} / 2\end{array}$ & $\begin{array}{l}S_{4}=t_{1}+T_{0} / 2 \\
S_{6}=t_{1}+t_{2}+T_{0} / 2 \\
S_{2}=T_{0} / 2\end{array}$ \\
\hline 6 & $\begin{array}{l}S_{1}=t_{1}+t_{2}+T_{0} / 2 \\
S_{3}=T_{0} / 2 \\
S_{5}=t_{1}+T_{0} / 2\end{array}$ & $\begin{array}{l}S_{4}=T_{0} / 2 \\
S_{6}=t_{1}+t_{2}+T_{0} / 2 \\
S_{2}=t_{2}+T_{0} / 2\end{array}$ \\
\hline
\end{tabular}

\section{SVPWM SIMULATION}

The SVPWM inverter simulation which feeding a three-phase induction motor has been done using the Matlab software package. The simulation is performed under the following conditions: $\mathrm{V}_{\mathrm{dc}}=$ $366 \mathrm{~V}$, switching frequency $=50 \mathrm{kHz}$, and three-

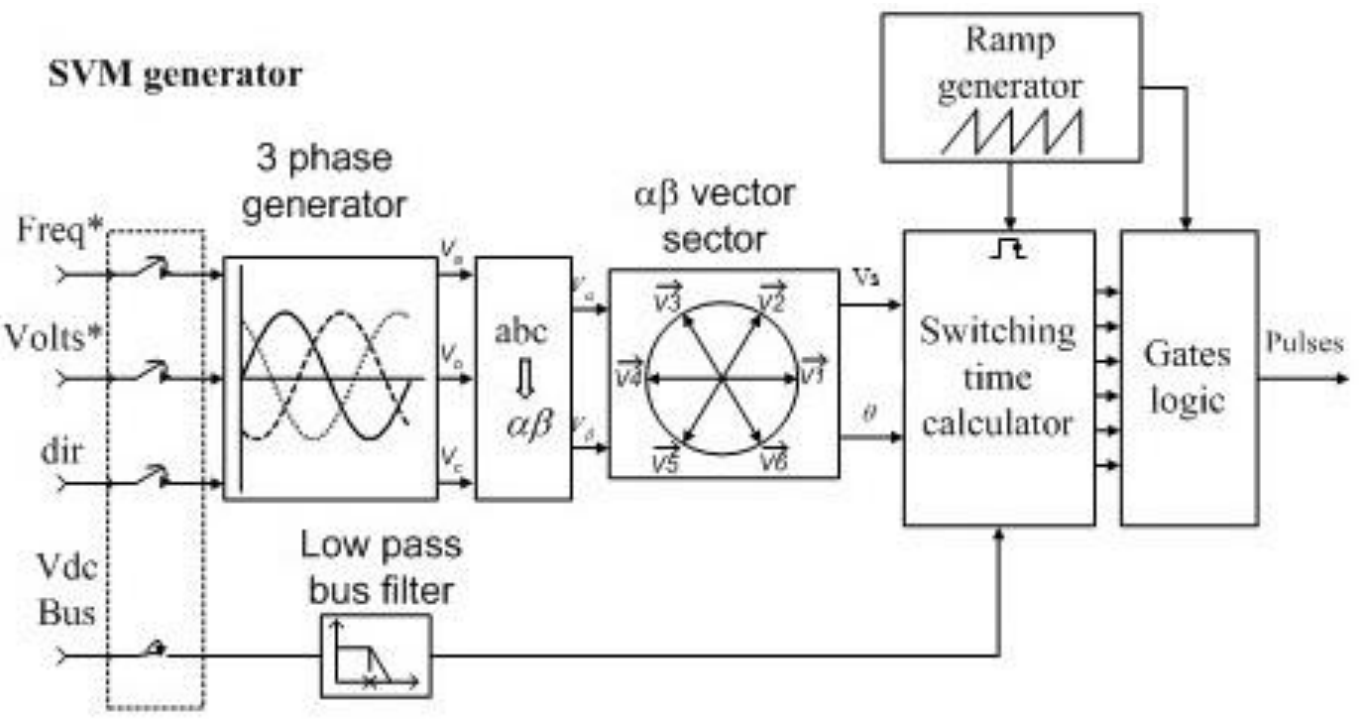

Fig6. Block diagram of SVPWM simulation system [13]

phase induction motor $\left(2238 \mathrm{VA}, 220 \mathrm{~V}(\mathrm{rms}), 60 \mathrm{~Hz}, \mathrm{R}_{\mathrm{s}}=0.435 \mathrm{ohm}, \mathrm{R}_{\mathrm{r}}{ }^{\prime}=0.861 \mathrm{ohm}, \mathrm{L}_{\mathrm{s}}=0.002 \mathrm{H}\right.$, $\mathrm{L}_{\mathrm{r}}{ }^{\prime}=0.002 \mathrm{H}, \mathrm{Lm}=69.31 \mathrm{H}, \mathrm{J}=0.089 \mathrm{~kg} \cdot \mathrm{m}^{\wedge} 2$, and $\mathrm{p}=2$ ). The block diagram of SVPWM simulation system is shown in Fig.6.

The load torque $(\mathrm{Tm})$ changes abruptly from 0 to $11 \mathrm{Nm}$ at $\mathrm{t}=0.5 \mathrm{~s}$ and from 11 to $-11 \mathrm{Nm}$ at $\mathrm{t}=1.5 \mathrm{~s}$. A PI Voltage/Frequency control method is used for open loop speed control of induction motor.

The stator current at different loading conditions is shown in Fig.10 (a). As it clear in Fig.10 (b) the motor current has low harmonic distortion. Reference speed and actual speed are shown in Fig.11. It can be seen that actual speed follows the reference speed with a reasonable accuracy. 


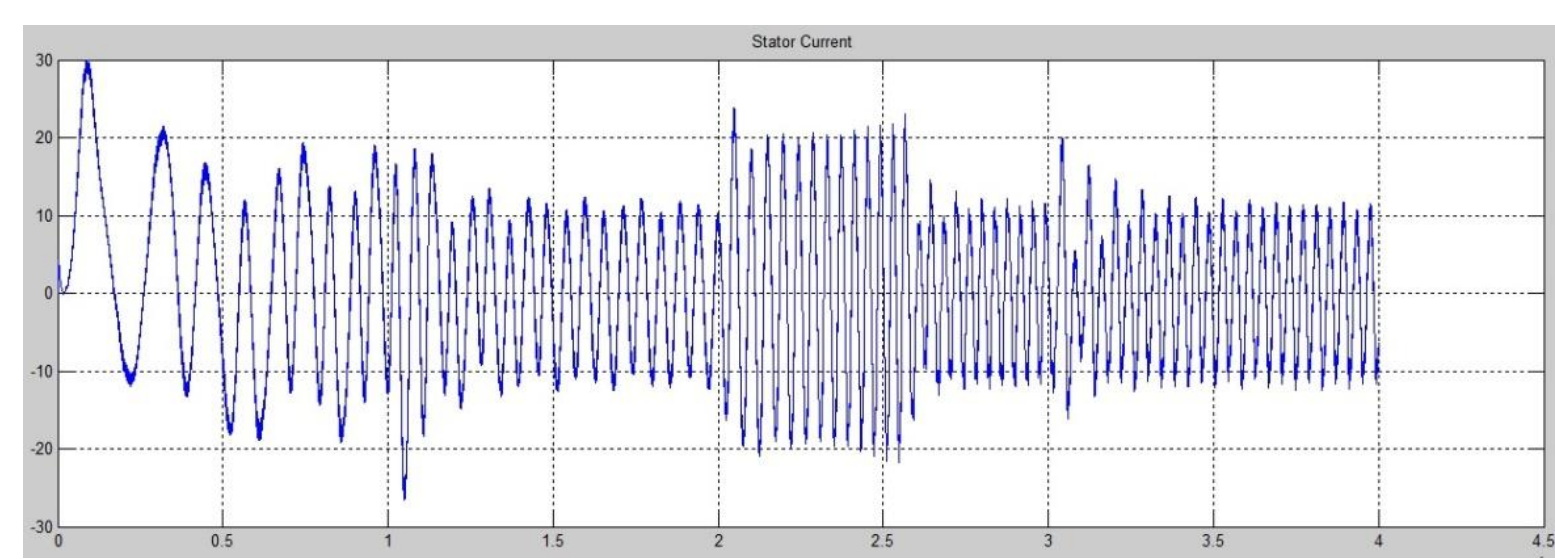

Fig10. (a) Stator current during load changing

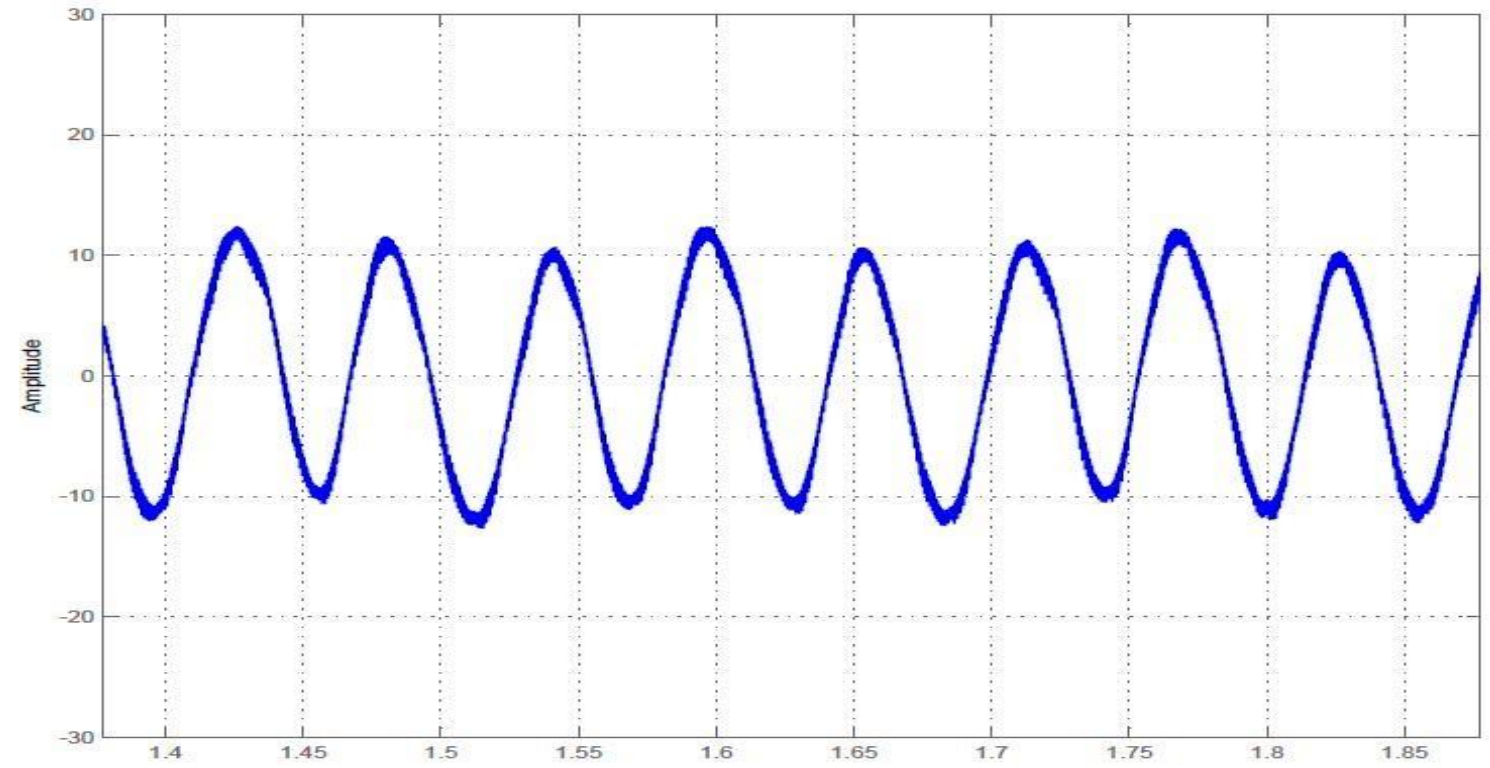

Fig10. (b) Stator current at $T m=11 \mathrm{Nm}$.

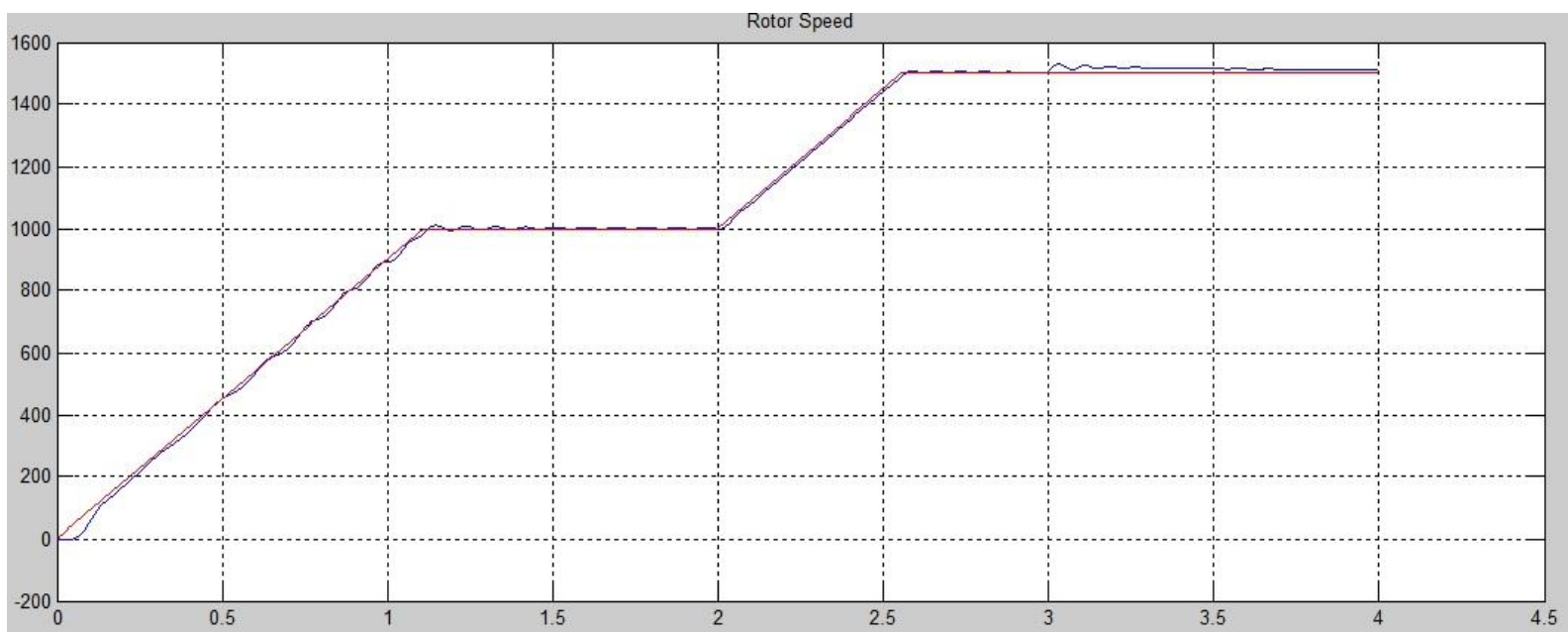

Fig11. Reference speed (red), actual speed (blue)

\section{CONCLuSion}

In this paper, a detailed simulation study of drive system consists of SVPWM inverter and a threephase induction motor has been introduced. The voltage/frequency control is used for speed control of induction motor with a reasonable degree of accuracy. The advantages of the proposed drive system are confirmed by the simulation results. The SVPWM inverter is used to offer increase in the output voltage and low output harmonic distortions compared with the conventional sinusoidal PWM inverter. 


\section{REFERENCES}

[1] Jamil Asghar, M.S.; Haroon Ashfaq, "Speed control of wound rotor induction motors by AC regulator based optimum voltage control," Power Electronics and Drive Systems, 2003.PEDS 2003. The Fifth International Conference on, vol.2, no., pp.1037, 1040 Vol.2, 17-20 Nov. 2003

[2] Lendenmann, Heinz et al. "Motoring Ahead". Retrieved Apr 18, 2012.

[3] Schönung, A.; Stemmler, H. (August 1964). "Geregelter Drehstrom-Umkehrantrieb mit gesteuertem Umrichter nach dem Unterschwingungsverfahren". BBC Mitteilungen (Brown Boveri et Cie) 51 (8/9): 555-577.

[4] Texas Instruments, "Field orientated control of three-phase AC motors," Application Report, February 1998.

[5] Maamoun, A.; Soliman, A.M., "Space-Vector PWM Inverter Feeding a Small Induction Motor," Mechatronics, ICM2007 4th IEEE International Conference on, vol., no., pp.1, 4, 8-10 May 2007

[6] Analog Devices, "Space vector modulation," Technical Report, September 1988.

[7] S. R. Bows, Y. S. Lai, "The relationship between space-vector modulation and regular sampled PWM," IEEE Trans. Industrial Electronics, Vol. 44, pp. 670-679, October 1997.

[8] M. Morimoto, K. Sumito, S. Sato, K. Oshitani, M. Ishida, S. Okuma, "High efficiency, unity power factor VVVF drive system of an induction motor," IEEE Trans. Power Electronics, Vol. 6, pp. 498-503, July 1991.

[9] A. Maamoun, A. M. Soliman, A. M. Kheireldin, "Near unity power factor single-phase to three-phase converter feeding an induction motor," Proc. IASTED Int. Conf: Artificial Intelligence and Applications, Innsbruck, Austria, pp. 131-135, February 2006.

[10] F. Zare, G. Ledwich, "Space vector modulation technique with reduced switching losses," Proc. Int. European Conf.: Power Electronics and Applications (EPE'99), Switzerland, pp. 1-7, September 1999.

[11] On line: www.mathworks.com

Citation: Rahim Ildarabadi (2017). Simulation Study of Space Vector Pulse Width Modulation Feeding a Three Phase Induction Motor, International Journal of Research Studies in Electrical and Electronics Engineering (IJRSEEE), 3(2), pp.19-25, DOI: http://dx.doi.org/10.20431/2454-9436.0302003.

Copyright: () 2017 Rahim Ildarabadi. This is an open-access article distributed under the terms of the Creative Commons Attribution License, which permits unrestricted use, distribution, and reproduction in any medium, provided the original author and source are credited 